\title{
Demandas globales para Trabajo Social. Comentario a la ponencia central de James Midgley
}

\author{
Global demands for Social Work. Comment to \\ James Midgley's central conference
}

\author{
PhD. Vishanthie Sewpaul \\ Vishanthie Sewpaul es Profesora Senior en la Natal University of Kwazulu Natal. School of Social Work and Community Develo- \\ pment Howard College Campus. Durban 4041.South Africa.SEWPAUL@ukzn.ac.za
}

\begin{abstract}
Resumen
El comentario a la ponencia del Profesor Midgley se refiere básicamente a resguardar el rol del trabajo social en el ejercicio de la solidaridad y la acción colectiva en un mundo donde los nacionalistas y los cosmopolitas no son auto-excluyentes uno del otro, y donde el trabajo social es demandado en unir fuerzas a nivel global como profesión organizada, con el objeto de desafiar a los sistemas globales de injusticia y al imperialismo unipolar que ha llegado a dominar al mundo.

Palabras claves (Unipolar, trabajo social, desigualdad, solidaridad, acción colectiva)

Abstract

This comment about Professor Midgley's presentation talks mainly about protecting social work's role in promoting solidarity and collective action, in a world where nationalists and cosmopolitans are not exclusive position, and where social work is demanded to gather forcers at global level, as organized profession, in order to challenge unequal global systems and the unipolar imperialism dominating the world.
\end{abstract}

Key words (Unipolar, social work, inequality, solidarity, collective action)

Damas y caballeros, me complace ofrecer la respuesta a la ponencia del Profesor Midgley. Si bien es en verdad un placer, es también una tarea desalentadora, dado el prestigio del Profesor Midgley y su prolífica escritura en el terreno del desarrollo social. Aunque el Sr. Midgley ha estado demasiado presente en mis clases de postgrado sobre políticas de bienestar y desarrollo social -en forma virtual, como para involucrarnos en muchos de sus textos- debo admitir que me siento un poco fuera de lugar al redactar hoy esta respuesta, pero haré mi mejor intento.

El Profesor Midgley avala la elección del tema del congreso -de modo que mis felicitaciones a los organizadores del Congreso por la elección- que señala que con el aumento del neoliberalismo y el énfasis puesto en el crecimiento económico más que en la redistribución, hemos visto aumentar la desigualdad en el mundo. La desigualdad se ha ampliado no sólo entre los así llamados países desarrollados y en las regiones en desarrollo, sino también en los países esencialmente capitalistas. Los Estados Unidos, uno de los países más poderosos del mundo, cuentan con más de 12 millones de personas que sufren de inseguridad alimentaria y que no saben de dónde llegará el próximo alimento que podrán consumir. Si bien las diferencias en los ingresos son importantes de por sí, el Profesor Midgley nos recuerda que no deberíamos olvidar la forma en que factores tales como la raza, el género y la etnia se intersectan con los factores económicos para mantener a las personas en posiciones de opresión y exclusión. No es accidental que las personas de color y principalmente las mujeres de color sigan siendo las personas más pobres y marginadas en cada uno de los continentes del planeta. Hace tiempo descartamos las teorías socio-biológicas de raza y género que intentaron ubicar a las personas de raza negra y a las mujeres en un estatus inferior como 
personas de menor inteligencia y pertenecientes a la menor de las especies. Como cientistas sociales reconocemos el impacto de las constelaciones de poder sesgadas y de las injusticias estructurales y las formas en que esto enmarca prácticas fuera de las cuales nosotros mismos tenemos dificultades para pensar. El control de nuestra conciencia ha sido tan poderoso, tan exitoso y tan completo que tenemos dificultad para creer que haya otros mundos fuera del capitalismo y más allá de éste. Aún cuando lo hacemos, nos quedamos cortos al imaginar un orden mundial alternativo que abarque ideales y prácticas redistributivas democráticas sociales. Estas, necesariamente, piden estructuras de gobiernos políticas y socioeconómicas que van contra la mayoría de las formas occidentales de democracia liberal.

En verdad, más que entender plenamente el "realismo" de los imperialistas unipolares y de cuestionar sus destructivos efectos, que es a lo que nos insta el Prof. Midgley, existe una llamada de muchos trabajadores sociales hacia los derechos humanos y la justicia social desde el interior del modo liberal que domina los derechos, principios y opciones. La democracia liberal supone la existencia de un individuo autónomo y libre, no sujeto a restricciones estructurales externas sobre sus elecciones. Hay una supuesta convergencia entre la democracia liberal y la ideología del libre mercado. De ahí el deseo de Bush de democratizar a Irak llevando a ese país por el camino liberal y su regocijo ante la perspectiva de que Fidel Castro renuncie de modo que Norteamérica pueda restaurar para los cubanos sus libertades y democracia. Yo digo que Cuba debe trazar su propio camino si el socialismo cubano no funciona para Cuba. La intervención norteamericana en Irak no ha contribuido a ninguna otra cosa aparte de una gran cantidad de muerte y destrucción. ¿Qué bien le ha aportado la forma norteamericana de democracia liberal a las mayorías del mundo, en donde la riqueza, la educación, la salud y el bienestar se concentran en las manos de unos pocos? Si la democracia social implica esforzarse por conseguir mayor igualdad entre las personas -donde ningún niño se vaya hambriento a la cama, donde ningún niño muera a causa de enfermedades que pueden prevenirse, y en donde todos los niños tengan acceso a la educación básica gratuita- ¿no es esta una mejor opción que la ideología de libre mercado? Los beneficios acumulados por una pequeña elite bajo el neoliberalismo y el poder que ésta ejerce al controlar la mayor parte del capital del mundo, además de los medios, significa que somos pocos lo que podemos pensar en posibilidades fuera de este marco.
Pero amigos, es importante -en especial si reconocemos que el dolor, los traumas y el desperdicio de vidas se apoyan en el capitalismo neoliberal y en la destrucción de los recursos del planeta- que cuestionemos el actual orden imperante en el mundo.

Existe un supuesto que se da por sentado en relación a una convergencia entre el mercado y la democracia, con el predominio capitalista norteamericano pregonados como fuente de moral y de práctica de la democracia, lo cual en realidad no puede estar más alejado de la verdad, tal como lo aclara un maravilloso escritor post-colonial, Samir Amin. Si la democracia en verdad se trata de derechos humanos, justicia social, participación del pueblo y respeto por la dignidad humana, ien dónde está su convergencia con el mercado, que no deja espacio para la justicia y la compasión, que crea indiferencia respecto de la desigualdad, el hambre, la explotación y el sufrimiento, que excluye las voces de los Otros, con un poder altamente centralizado que se negocia en la Banca Mundial, el Fondo Monetario Internacional, La Organización Mundial del Comercio y por los súper poderes del mundo? Si el acceso a la información es central para una democracia que se profundiza, ¿cómo puede haber democracia si la información y las propias ideas que generamos se transforman en materia prima? ¿Cuál es la convergencia entre democracia y mercado cuando los derechos de propiedad intelectual (DPIs) que incorporan las leyes de patentes, se diseñan sólo en interés del lucro (por ejemplo, aquellos de las empresas farmacológicas multinacionales, permiten que muera una tercera parte de la población del Mundo de los Dos Tercios? ¿Qué son lo liberal y la libertad individual, si tales libertades significan la restringida opción por la enfermedad, la inanición, el hambre y la muerte para una gran parte de la población del mundo? Chang y Grabel (2004, p. 94) afirman que "se ha dejado fuera de la noción liberal sobre los derechos de propiedad intelectual, la posibilidad de que el 'lucro social' o bienestar social puedan servir como estímulo para la innovación o que los gobiernos deberían estar en posesión de esos derechos" más que los individuos o la empresa privada. Amin (2001, p. 9) concluye que "... las relaciones capitalistas globales de mercado han generado desigualdades cada vez mayores. La teoría de la convergencia -la noción de que mercado y democracia confluyen- es hoy en día sólo un dogma; una teoría de políticas imaginarias", con mucho de lo que se habla acerca de democracia reflejando la imposición de los formuladores de las políticas que han usurpado el poder en los Estados Unidos. 
El Profesor Midgley nos ofrece una comprensión teórica al proporcionarnos cuatro amplias categorías de respuesta al poder global. Los ideales optimistas e igualitarios de los cosmopolitas que favorecen la cooperación internacional con el mismo trato para todos los estados - naciones; la protección de las identidades e intereses nacionales de los etno-nacionalistas; la negación del mundo interconectado de los aislacionistas ${ }^{1}$; y los realistas internacionales. Es al interior de esta última categoría donde están los imperialistas unipolares que basan sus argumentos en el principio darwiniano del determinismo biológico y de la supervivencia del que mejor se adapte; la "naturalidad" y la inevitabilidad del dominio de las naciones más débiles por parte de las más fuertes. Según lo dicta la dinámica actual del mundo, los Estados Unidos son los que ostentan esta posición -sólo que no se trata del benevolente Leviatán que utiliza su poder militar, diplomático y económico para mantener la paz en el mundo como creen algunos imperialistas unipolares. Sabemos que la verdad es lo opuesto. El Profesor Midgley menciona apenas algunos de varios ejemplos de los efectos destructivos del unipolarismo norteamericano- su compromiso con hacer que la democracia liberal y el libre mercado dominen el mundo, la guerra en Irak, y las consecuencias de las políticas de abstinencia de los conservadores Norteamericanos con respecto a la prevención del VIH en Uganda.

Si bien los sistemas de clasificación y categorización pueden tener valor y ayudarnos a encontrarle el sentido a un mundo muy caótico y complejo, al mismo tiempo contienen el potencial de imponernos una camisa de fuerza. No he estudiado las complejidades en absoluto. Sin embargo, no estoy segura de que no se pueda ser, por ejemplo, nacionalista y cosmopolita al mismo tiempo. ¿Podría ser nuestra fidelidad hacia la identificación nacional, y nuestra necesidad de ella, la antítesis de los ideales cosmopolitas de ciudadanía global? Las identidades, como todos sabemos, son fluidas, dinámicas y cambiantes -dependiendo de diversos factores de contexto e históricos. Además, si bien mucho de nuestra retórica en el trabajo social acerca de los derechos humanos y la justicia social pueden conjurar las imágenes de la ciudadanía global, las definiciones de ciudadanía- con su enfoque sobre los derechos y responsabilidades de los pueblos en relación a una nación-estado específico, indican que todos los aspectos sustantivos de la ciudadanía se apoyan a nivel nacional. De modo que, sin importar lo cosmopolita que se pueda ser en términos de perspectiva la realidad es que esos marcos políticos y legislativos con respecto a la ciudadanía se definen a niveles nacionales. Los sistemas de clasificación a veces constituyen también la apariencia tras la cual se ocultan los académicos y los cientistas sociales. Facilita un lenguaje de objetividad, neutralidad y una postura de libre mercado (value - free) ante una problemática demasiado repleta de valor (value laden). Estoy muy complacida de señalar que el Profesor Midgley no usa esta clasificación con esta finalidad. Por el contrario, llama en forma explícita a los trabajadores sociales a estar concientes de las consecuencias de la ideología y prácticas unipolares y a nosotros nos propone cuestionarlas. Nos re-repite aquello a lo que nos han llamado muchos trabajadores sociales en todo el mundo. Su llamado concuerda plenamente con la declaración de visión y misión de la Asociación Internacional de Escuelas de Trabajo Social (AIETS) ${ }^{2}$. La declaración de políticas sobre derechos humanos de la Federación Internacional de Trabajadores Sociales (FITS) ${ }^{3}$ y de la AIETS reconoce el lugar de la solidaridad y de la acción colectiva. Pienso que llegó el momento de responder a este llamado en forma activa. Hay muchos trabajadores sociales profesionales, quienes ya sea dentro de sus capacidades individuales, o como parte de sus organizaciones nacionales de sociedad civil locales o nacionales, están cuestionando los sistemas globales de injusticia, exclusión y marginación. Es poco afortunado que como profesión organizada no hayamos sido capaces de hacerlo a nivel global. Necesitamos desarrollar una red global de trabajadores sociales que se involucre, que entable diálogos, que desarrolle alianzas con otros movimientos de la sociedad civil y que desafíe a los actuales esquemas del imperialismo unipolar y a la ideología de libre mercado que domina cada aspecto de nuestras vidas y de las vidas de las personas para las que trabajamos. El trabajo social, como disciplina, se ve afectado por ellos en todo el globo. Los trabajadores sociales han escrito sobre el tema, y algunos han protestado contra el creciente énfa-

1 Isolationism: una política extranjera que combina una política militar no intervencionista y una política de nacionalismo económico (proteccionismo). (N. Editor).

2 IASSW.

3 IFSW. 
sis en las prácticas, resultados, auditorías, nóminas salariales con base en la evidencia, a expensas del énfasis del trabajador social en la protección, los valores, los procesos y la reflexividad. Los trabajadores sociales deben trabajar bajo enormes presiones con el aumento de la privatización de los servicios; la reducción de la salud, la educación y el bienestar, y la creciente desigualdad en el mundo. Y lo que es más importante, vemos, somos testigos y experimentamos, los efectos de éstos en las vidas de las personas para las que trabajamos. Necesitamos comenzar a dialogar a nivel global. Necesitamos soñar con la posibilidad de órdenes mundiales alternativos. Si realmente podemos comenzar a visionar ese sueño tal vez podamos comenzar a darle alguna sustancia y ofrecer esperanzas para el futuro. Es un imperativo moral y no deberíamos rendirlo ante los políticos, cientistas políticos, sociólogos y anarquistas del mundo. El trabajo social necesita unir fuerzas a nivel global como profesión organizada para desafiar a los sistemas globales de injusticia y al imperialismo unipolar que ha llegado a dominar al mundo.

\section{Referencias}

AMIN, S. (2001) Imperialism and Globalization. Monthly Review. 53, 2 http://www.monthyreview.org/060lamin. htm.

CHANG, H. AND GRABEL, I. (2004) Reclaiming Development: An Alternative Economic Policy Manual. London: Zed Books. 